\title{
Development of a novel cycling impact-sliding wear rig to investigate the complex friction motion
}

\author{
Zhenbing CAI ${ }^{*}$, Zhiqiang CHEN, Yang SUN, Jianying JIN, Jinfang PENG, Minhao ZHU \\ Tribology Research Institute, Key Lab of Advanced Technologies of Materials, Southwest Jiaotong University, Chengdu 610031, China \\ Received: 27 June 2017 / Revised: 20 August 2017 / Accepted: 22 August 2017 \\ (C) The author(s) 2017. This article is published with open access at Springerlink.com
}

\begin{abstract}
In many industrial devices, impact-sliding wear is caused by a variety of complex vibrations between the contacted interfaces. Under actual conditions, impact and sliding motions do not occur in only one direction, and different complex impact-sliding motions exist on the tribology surfaces. In this study, an impact-sliding wear test rig is developed to investigate the wear effect of different complex motions. Using this rig, multi-type impact-sliding wear effects are realized and measured, such as those derived from unidirectional, reciprocating, and multi-mode combination motions. These three types of impact-sliding wear running behavior are tested and the wear damage mechanism is discussed.
\end{abstract}

Keywords: impact-sliding wear; wear test rig; complex friction motions; wear damage mechanism

\section{Introduction}

In actual working conditions, the relative movement between friction interfaces does not occur in only one but in multiple directions [1]. In recent years, many researchers have recognized the great significance of studying the wear caused by multidirectional movements. Considering the research on fretting wear as an example, Zhu et al. [2,3] proposed a dual-motion fretting combination with tangential and radial directions. Cai et al. $[4,5]$ reported on complex axial rotation motion, model-torsional, rotational, and dualrotary fretting. Impact wear (or erosion wear) is the surface damage caused by the repeated dynamic contact and impact between two objects [6-8]. Additionally, erosive wear is caused by the impact of solid or liquid particles (e.g., sand blown by the wind or a fluid) against a surface, and this type of impact wear considerably affects a body. Sliding wear damages the surface because of the tangential relative motion of the two interfaces [9]. Impact-sliding fretting wear means that tangential friction occurs simultaneously with impact forces acting upon mechanical components. This combination of motions will increase fretting wear [10-15] because the wear surface will be subjected to punch cutting, chipping, and other damages. At the same time, the material of the wear surface layer will harden and form cracks [16], and then, the connection and expansion of cracks can cause material loss and failure.

Impact-sliding wear behavior occurs in many industrial devices, such as geological and petroleum industry drilling systems [17], steam generators in nuclear power plants (Fig. 1), automobile valve combustion chambers [18], and the interfaces between tenons and groove sin aircraft and gas turbines. Different impact-sliding movements have different tribology processes because they contain a variety of complex motions, such as unidirectional (Fig. 3(c)), reciprocating (Fig. 4(c)), reciprocating with peak force atone cycle (Fig. 5(c)), and multi-mode combination motions. To investigate the effect of the different complex motions on wear, a novel impact-sliding test rig is designed and developed in this study.

* Corresponding author: Zhenbing CAI, E-mail: caizb@swjtu.cn 


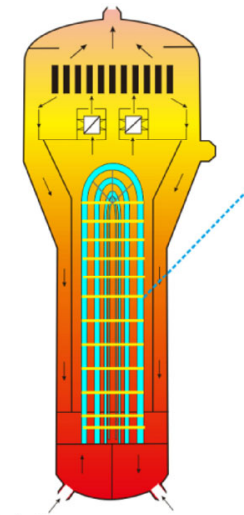

(a) Steam generator

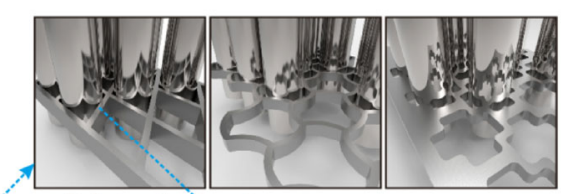

(b) Anti-abrasion support sutructure

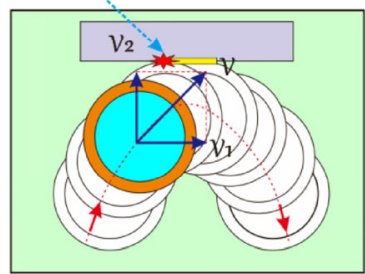

(c) The motion of impact-fretting wear
Fig. 1 Schematic of impact-sliding fretting wear.

The following aspects were considered in designing the rig:

(i) The machine can release multiple functions for conducting different types of wear tests. Currently, most testing machines only test a single function, such as single linear motion (sliding) or rotary motion.

(ii) The relationship between impact and sliding motions must be controlled to simulate multiple impact-sliding conditions. Some research works had focused on the impact-sliding motion and some meaningful results could be found [19-21]. However, most of the related research was concerned with the material damage induced by the impact-sliding process under a specific track, without paying attention to the tribology behavior under different types of movement.

(iii) Impact and sliding forces should be measured to determine their change under the tribology process [22-24]. However, these parameters have been neglected in most testing machines. The clamp for the experiment must meet different interface requirements, including ball-on-flat, flat-on-cylinder, crossed cylinder configuration, and face-to-face contact.

After considering the above factors, an impactsliding wear test machine was developed to study wear under three different complex motions and the friction and wear behavior was explored.

\section{Equipment description}

\subsection{Impact-sliding test rig}

The impact-sliding fretting wear test machine should have the capability to evaluate the influential para- meters, such as impact force, slip amplitude, and frequency. The test machine should have multiple functions and perform different motion fretting wear tests (impact, sliding, and impact-sliding fretting wear). Moreover, it should realize multiple complex impactsliding motions, such as unidirectional, reciprocating, reciprocating with peak force at one end, and multimode combination motions.

The schematic of the impact-sliding test rig is shown in Fig. 2(a) and an actual photographs included in Figs. 2(b) and 2(c). The upper specimens are fixed at the end of the vertical shaft, which moves in the $z$-direction. The lower specimen is fixed on the horizontal shaft, which moves in the $x$-direction. Two voice coil motors are used to apply impact-fretting motion. Each shaft has a built-in magnetic grating transducer for measuring the displacement of the voice coil motors. The amplitude of the specimens is measured by two extra magnetic grating transducers, mounted near the specimen. Both voice coil motors oscillate with a sinusoidal wave. A Galil control is performed to attain the required amplitude, which ranges from 10 to $500 \mu \mathrm{m}$. The impact and tangential forces are measured with a two-dimensional force sensor $\left(F_{X}, F_{Z}\right)$. The inertia forces in the $z$-direction are measured with an acceleration transducer. The data are recorded with a personal computer (PC).

The servo motor has two functions: (1) To lift the Z-direction impact motion module in order to separate the upper and lower samples, thus facilitating their replacement; and (2) to drop the Z-direction impact motion module slowly, so as to slowly reduce the distance between the upper and lower samples, and reach the required impact force value.

The upper control system was created by means of the graphical programming language "Labview", as shown in Fig. 2(d). It mainly consists of five parts: (1) device control, (2) test parameter, (3) acquisition settings, (4) sampling point number, and (5) data display section. The device control section includes the start, stop, and program of the voice coil motor. The test dates can be collected automatically by setting the sampling mode in automatic acquisition and setting the sampling points. The display section shows the displacement and force in the impact and sliding directions separately. 


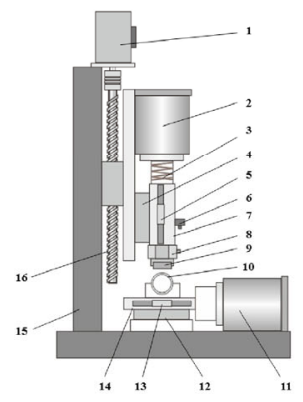

(a) Diagram

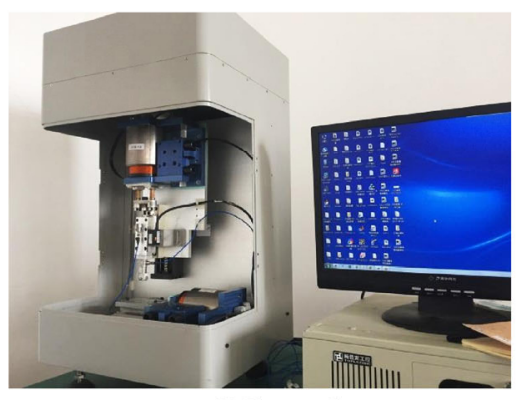

(b) Photograph

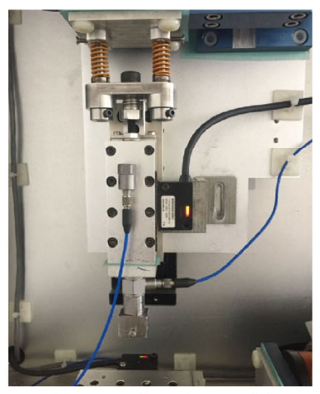

(c) Impact direction module

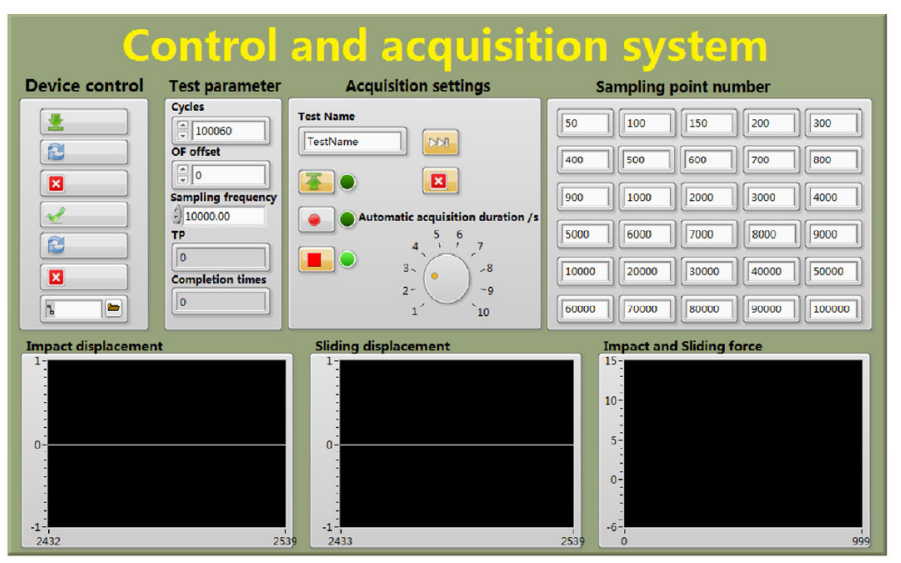

(d) Control and acquisition system of the impact-sliding test machine

Fig. 2 Impact-sliding wear test rig ( 1 - servo motor, $2-z$-voice coil motor, 3 -spring damper, $4-z$-linear slider, $5-z$-magnetic grating transducer, 6 - acceleration transducer, 7 -joint plate, 8 - two-dimensional force sensor $\left(F_{X}, F_{Z}\right)$, 9-upper specimen, 10 - lower specimen, $11-x$-voice coil motor, $12-x$-linear slider, 13-x-magnetic grating transducer, 14-platform, 15-frame, 16-lead screw).

\subsection{Four different impact-sliding processes}

As mentioned above, the impact-sliding wear will have different performances under varied complex motions. Four complex impact-sliding motions(1) unidirectional, (2) reciprocating, (3) reciprocating with peak force at one cycle, and (4) multi-mode combination motions - can be achieved by changing the relationship (frequency and phase difference) between the two voice coil motors. Dual-motions operate in accordance with the sinusoidal curve. During the test, impact occurs when the $z$-displacement is close to its maximum, which means that the upper specimen moves from the upper to bottom position. Under the same impact force, different complex motions can be achieved by changing the initial phase, frequency, and $x$-displacement of the horizontal shaft motor.

\subsubsection{Unidirectional motion wear}

The frequencies of the $Z$ - and $X$-direction voice coil motors are the same under unidirectional motion wear.
Furthermore, the initial phases of the bidirectional motors differ by $\pi / 2$ (Fig. 3(a)). The Z-displacement attains its minimum value (point 2 ) when the positive $x$-displacement becomes negative. Impact-sliding behavior occurs near this area. Wear behavior is absent when the negative $X$-displacement becomes positive, because at that point $Z$-displacement is maximum (point 4), which means that the upper specimen is farthest from the lower specimen. The dual-direction combined movement is a closed circularity with impact-sliding at the lowest point (point 2) (Fig. 3(b)). Thus, each impact force is followed by one tangential force in the same direction, in each cycle (Fig. 3(c)). Moreover, the wear debris moves to one side and is easily discharged to the outside owing to the unidirectional sliding force.

\subsubsection{Reciprocating motion wear}

During this situation, the frequency of the $z$-direction voice motor is twice that of the X-direction voice motor (Fig. 4(a)).The Z-displacement attains its first 


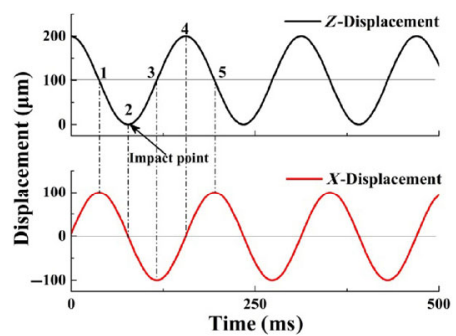

(a) Displacement of two shafts

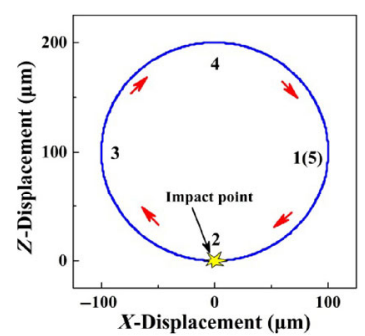

(b) Composed trajectory

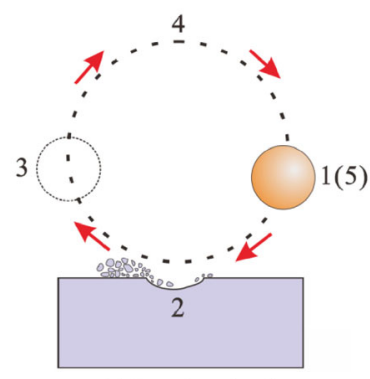

(c) Running sketch

Fig. 3 Theoretical displacement of the two directions and composed trajectory under unidirectional motion.

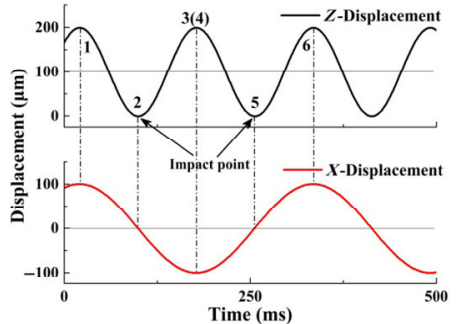

(a) Displacement of two shafts

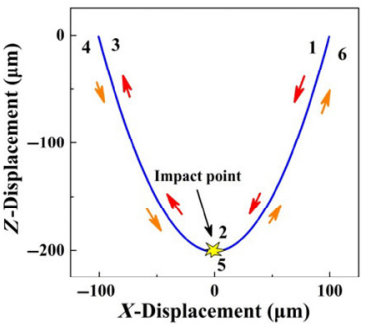

(b) Composed trajectory

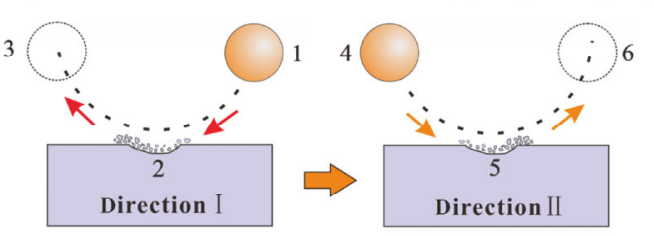

(c) Running sketch

Fig. 4 Theoretical displacement of the two directions and composed trajectory under reciprocating motion.

minimum (point 2) as the positive $X$-displacement becomes negative. Then $Z$-displacement attains the second minimum (point 5) as the negative $x$-displacement becomes positive. The composed trajectory of the two directions is a bidirectional parabola (Fig. 4(b)). In the two adjacent impacts, the impact-sliding behavior occurs twice in opposite sliding force directions (Fig. 4(c)). Thus, under the effect of direction I sliding force, the wear debris moves to one side. Under the effect of direction II sliding force, the wear debris moves to the other side. Therefore, the wear debris is not easily moved to the outside and it accumulates in the contact zone.

\subsubsection{Reciprocating motion wear with peak force at one end}

Reciprocating motion wear with peak force at one end is common in engine valve surfaces. The frequency and initial phases of the two directions are the same (Fig. 5(a)). When the $z$-displacement is at its minimum value (points 3 and 4 ), the $x$-displacement is also at the minimum value, indicating that the lower specimen reaches one end during impact. The composed trajectory of the two directions is a dualdirectional straight line (Fig. 5(b)). During this impactsliding process, the direction of the lower specimen changes, which results in the opposite sliding movement twice with one impact (Fig. 5(c)). In this situation, when the ball descends to the lowest point, the impact and sliding forces change to their maximum values, and then the ball returns. Thus, the wear debris is squeezed in the wear scar.

\subsubsection{Multi-mode combination motion}

In this case, the unidirectional, reciprocating, and other motions occur. During impact, the sliding velocity is unknown and maybe high or zero. Thus, the effective sliding displacement in each cycle is not specified.

All the curves motioned above are based on a theoretical analysis. During the actual test process, the curve will show a different behavior once the test

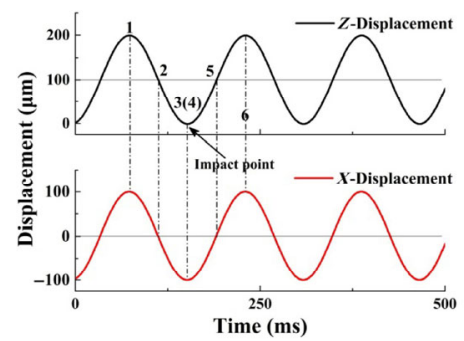

(a) Displacement of two shafts

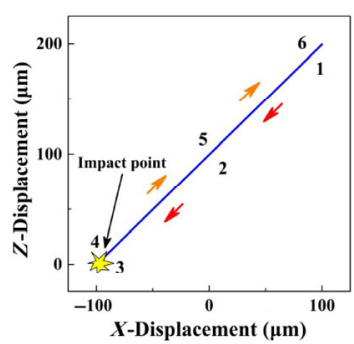

(b) Composed trajectory

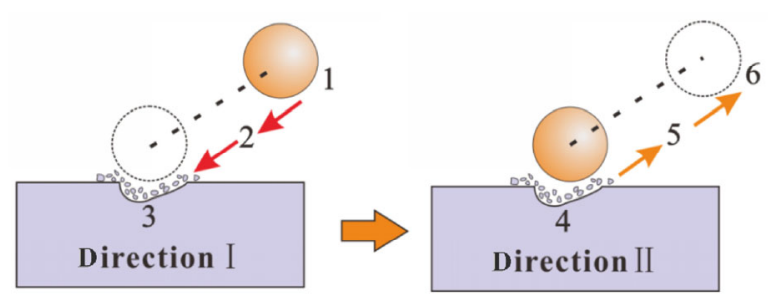

(c) Running sketch

Fig. 5 Theoretical displacement of the two directions and composed trajectory under reciprocating motion wear with peak force at one end. 
has been carried out. In any mode of friction or wear, the wear debris (three body) can affect the tribology behavior in the contact interface. Therefore, research on the debris motion behavior during the friction process is important and meaningful.

\section{Experimental procedure}

\subsection{Specimens and testing analysis}

A tube/cylindrical impact-sliding wear model was used (Fig. 6) to verify the functionality of this device (unidirectional, reciprocating, and multi-mode combination motions) regarding wear. To release the impact-sliding fretting wear, the column specimen was used as the upper specimen in the impact direction (z-direction) and the tube as the lower specimen in the horizontal direction (X-direction).

An Inconel 690 alloy tube (heat-transfer tube material for steam generators in nuclear power plants) and 304 bearing steel roller were selected as test specimens. The Inconel 690 alloy tube had the following specifications: external diameter, $17.48 \mathrm{~mm}$; inner diameter, $15.44 \mathrm{~mm}$; length, $35 \mathrm{~mm}$; and roughness $\mathrm{Ra}=0.4 \mu \mathrm{m}$. The roller specimen size was $\varnothing 10 \mathrm{~mm} \times$ $20 \mathrm{~mm}$. Before testing, all specimens were ultrasonically cleaned with ethyl alcohol and then dried with hot compressed air.

To compare the tribological performance under different complex motions and impact forces, two test groups were designed. The details of the experimental parameters are presented in Table1.

In testing different complex motions, to guarantee the same impact force and contact duration in each

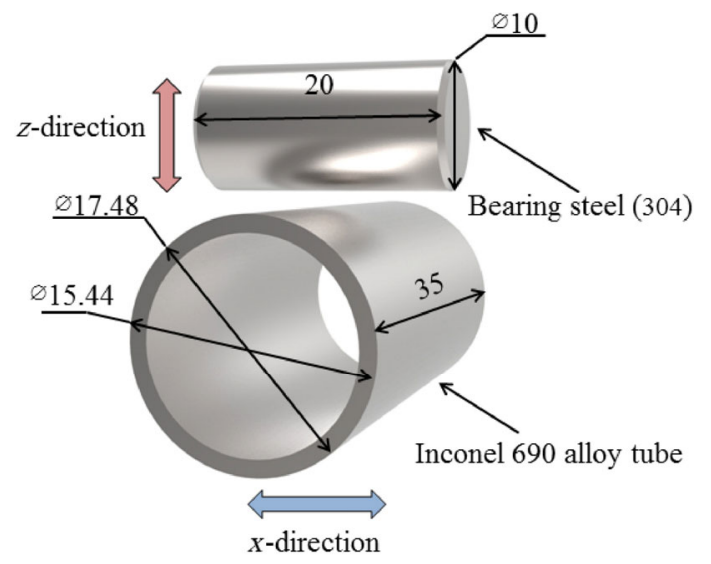

Fig. 6 Specimens used in the verification test (dimensions in $\mathrm{mm}$ ). cycle, the operating radius of the $z$-shaft motor was kept the same $(150 \mu \mathrm{m})$ in all the tests. To ensure the same actual contact displacement in the three tests, which is approximately $100 \mu \mathrm{m}$, the radius of the $x$-shaft motor was varied: $55 \mu \mathrm{m}, 100 \mu \mathrm{m}$, and $50 \mu \mathrm{m}$ in the unidirectional, reciprocating, and multi-mode combination motion tests, respectively. The multimode combination motion was achieved by setting the frequency at $10 \mathrm{~Hz}$ in $x$-direction and $10 \mathrm{~Hz}$ in $z$-direction. Thus, every 20 impact cycles ( $2 \mathrm{~s}$ ) constituted a full cycle. In the different impact force test, the sliding displacement of the $x$-shaft motor was set at the same $150 \mu \mathrm{m}$. Every test condition was repeated three times to ensure reliability of the results.

Force and displacement were measured sporadically during the tests. After the impact-sliding wear test, the wear scar morphology was observed using an optical microscope (OLYMPUS-BX60M) and scanning electron microscopy (SEM, JSM-6610, JOEL). A contour GT-type was used to analyze the micro surface morphology and wear depth of the scar. Then, the wear scar area was calculated.

\subsection{Results and discussion}

\subsubsection{Running trajectory}

Figures 7-9 show the trajectory of the specimen under the unidirectional, reciprocating, and multi-mode combination motions, respectively. Figures 7(a) and 8(a) show the motion track of the lower specimen in the $x$-direction and that of the upper specimen in the Z-direction, under different motions. The $X$ - and $Z$-direction motions constitute the relative trajectory, as shown in Figs.7(b) and 8(b). The bottom of the trajectory changes to a straight line because of the impact force and position restriction from the lower specimen. The length of the straight line represents the actual sliding displacement during each impact.

In the unidirectional impact-sliding test mode (Fig. 7), the trajectory is closed and does not change in each cycle, whereas in the reciprocating test (Fig. 8), the composed trajectory is different and symmetrical between two adjacent cycles. Moreover, the direction of the composed trajectory changes every other cycle. In the multi-mode combination impact-sliding test, the relationship (phase) between the $X$ and $Z$ motions changes with time. Figure 9 shows the running 
Table 1 Test parameters.

\begin{tabular}{ccccc}
\hline Group number & I & II \\
\cline { 2 - 5 } Complex motions & Unidirectional & Reciprocating & Multi-mode combination & Unidirectional \\
\hline Impact force, $F_{\mathrm{i}}(\mathrm{N})$ & 12.5 & 12.5 & 12.5 & $15,20,25,30$ \\
Effective sliding displacement $(\mu \mathrm{m})$ & 100 & 100 & 100 & 10 \\
Impact Frequency $(\mathrm{Hz})$ & 10 & 10 & $10^{5}$ & $10^{5}$ \\
Number of cycles & $10^{5}$ & 23 & 23 & 23 \\
Temperature $\left({ }^{\circ} \mathrm{C}\right)$ & 23 & 3 & 3 \\
Repeated times & 3 & & 3 \\
\hline
\end{tabular}

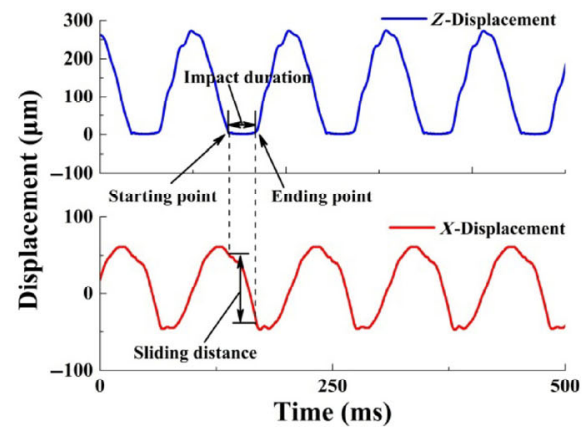

(a) Displacement of the two shafts

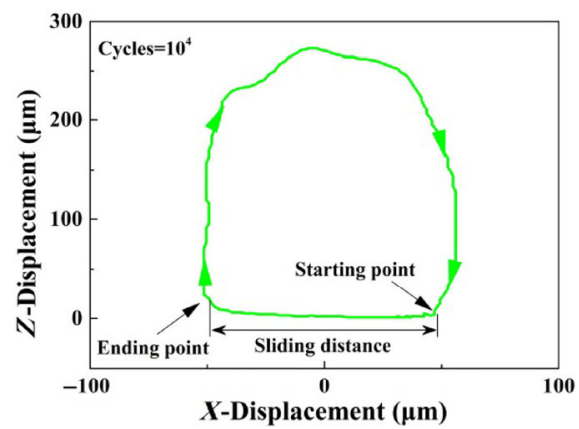

(b) Composed trajectory

Fig. 7 Real displacement of the two directions and composed trajectory under unidirectional motion.

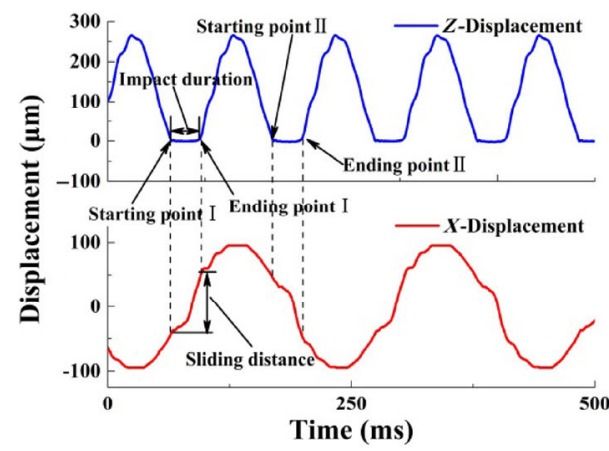

(a) Displacement of the two shafts

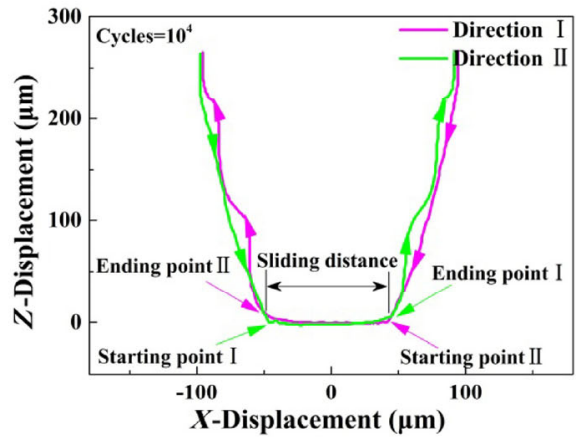

(b) Composed trajectory

Fig. 8 Real displacement of the two directions and its composed trajectory under reciprocating motion.

trajectory of the 20 adjacent cycles and a single cycle after $10^{4}$ cycles. In these cycles, the length of the straight line and the inflection point position were different from each other (Fig. 9(b)), which indicated that sliding displacement and starting impact point are different in each cycle.

\subsubsection{Force and friction coefficient}

The impact and sliding force were measured during the unidirectional and reciprocating tests, as shown in Figs. 10 and 11. Although the impact force (z-direction) is the same, the sliding force ( $x$-direction) differs. In the unidirectional test, the sliding force is positive, where as that in the reciprocating test is negative, which indicates that the specimen is under a twodirectional sliding force. The absolute value of the sliding force changes throughout the tests.

At a certain cycle, the average value of the impact and sliding peak forces in five adjacent cycles is selected as the force value. In addition, the ratio of sliding peak force to impact force is selected as the friction coefficient. Figure 12 represents the evolution of 


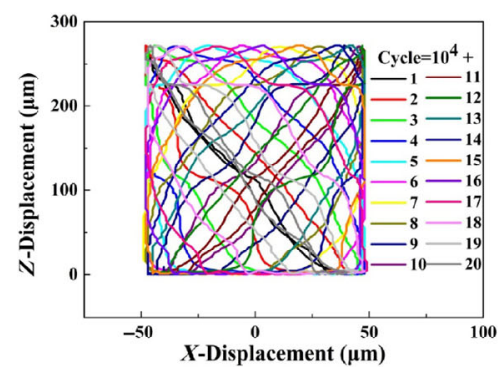

(a) Multiple running track

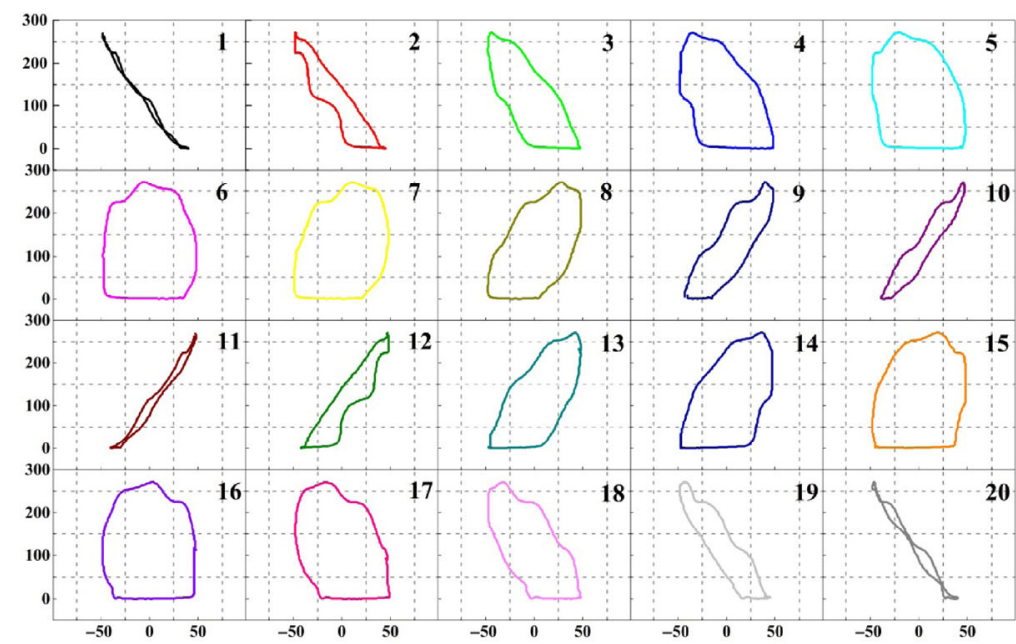

(b) Single track in each cycle

Fig. 9 Composed trajectory under multi-mode combination motion.

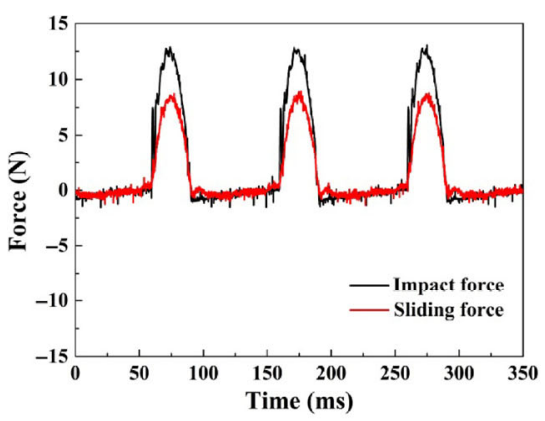

(a) Unidirectional

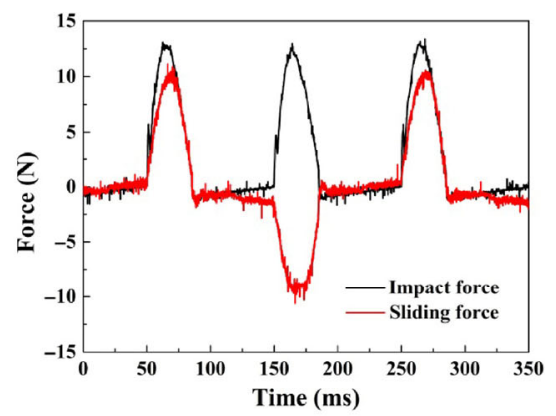

(b) Reciprocating

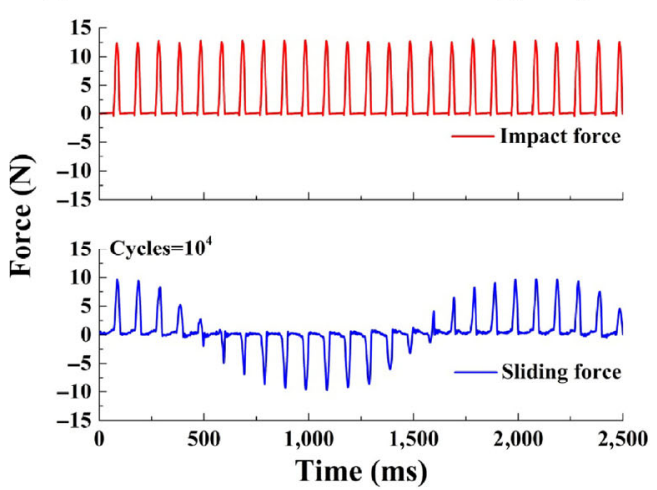

(c) Multi-mode combination

Fig. 10 Impact and sliding force, cycles $=10^{4}$.

the friction coefficient with the number of fretting cycles .The friction coefficient (COF) has four stages: (1) ascending, (2) peak stage, (3) descending, and (4) slowly rising stages. At the same cycle, the COF of the reciprocating test is higher than that of the unidirectional test. The peak value of COF is 0.9 in the reciprocating test and 0.78 in the unidirectional test.
In the multi-mode combination test, under the same impact force, the peak and direction of the sliding force were changed, and every 20 cycles (about 2,000 ms) constituted a large cycle (Fig. 10(c)). The sliding force has two directions and the peak is unstable; thus, the specific parameters are difficult to analyze statistically and the COF is ignored. 


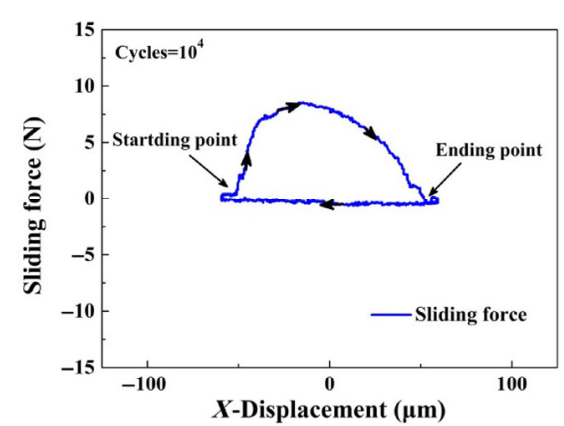

(a) Unidirectional

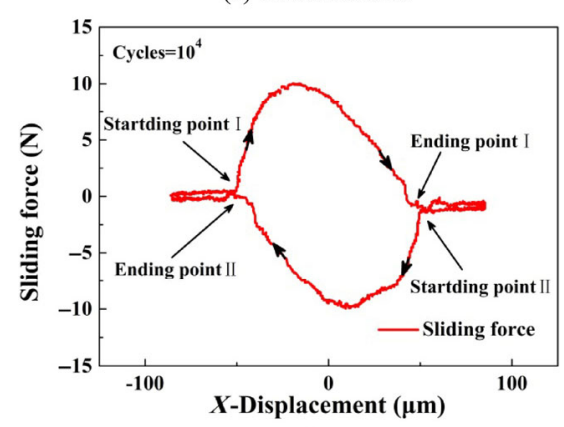

(b) Reciprocating

Fig. 11 Sliding force with $x$-displacement in unidirectional and reciprocating tests mode, cycles $=10^{4}$.

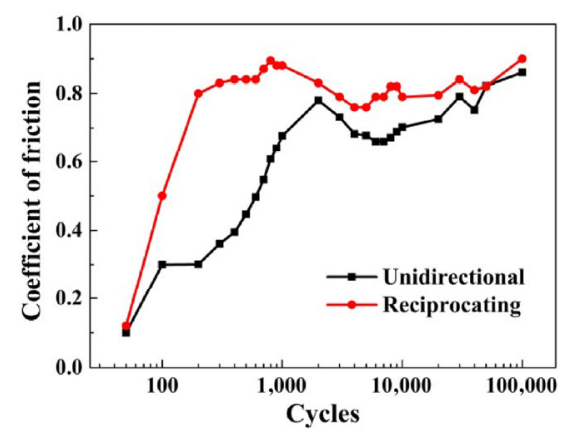

Fig. 12 Evolution of the friction coefficient with the number of cycles.

\subsubsection{Wear scar morphology}

Figure 13 shows the optical morphology (OM) and 3D micrographs of the tube wear scars. Under unidirectional impact-sliding, the wear area is the largest at approximately $0.66 \mathrm{~mm}^{2}$ (shown in Fig. 15), and it reaches $0.36 \mathrm{~mm}^{2}$ in the multi-mode combination test situation.

Figure 14 presents the profile of the worn tubes, along the axial and radial directions. Under unidirectional motion, the wear scar of the tube had the greatest depth at approximately $7.6 \mu \mathrm{m}$ in the axial direction and $9.1 \mu \mathrm{m}$ in the radial direction. The protruding part exhibits wear debris that was caused by the unidirectional sliding force, as shown in Fig. 14(b).

The differences in wear scars can be explained as follows. Under unidirectional motion, the wear debris moves to one side of the tube (Fig. 3(c)), and thus, it easily moved to the outside zone. When the tube is under reciprocating or multi-mode combination motions, the wear debris accumulates in the contact enter owing to the dual-directional sliding force. Thus, the wear debris protects the surface and reduces the wear rate. Moreover, in the multi-mode combination test, the effective sliding displacements are different and maybe long, short, or zero in each cycle (Fig. 9(b)), but they are always shorter than in the other two tests. Therefore, in the multi-mode combination test, the wear area is the smallest.

In the reciprocal motion test, the wear debris is more easily accumulated in the wear area because it

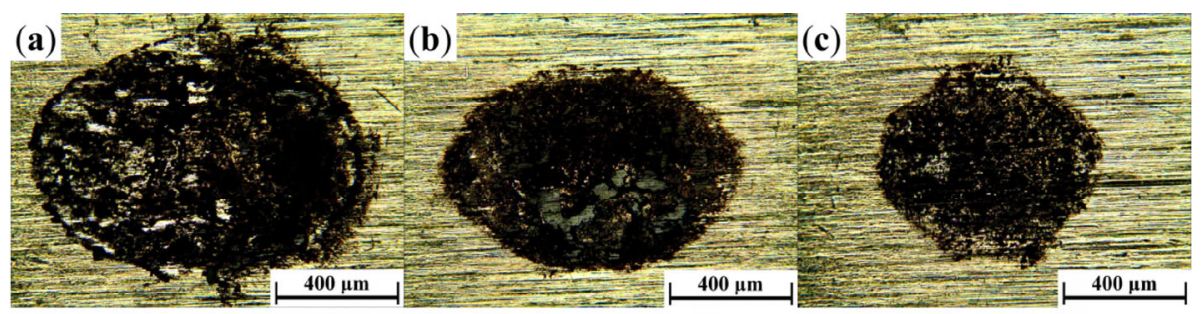

(d)

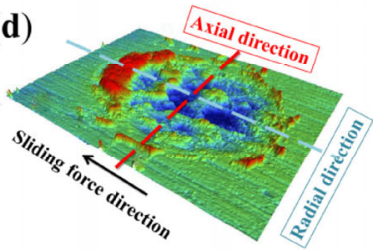

(e)

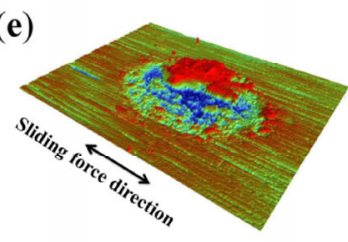

(f)

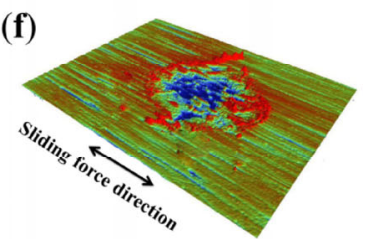

Fig. $13 \mathrm{OM}$ and 3D micrographs of tube wear scars under different complex motions. (a, d) Unidirectional, (b, e) reciprocating, and (c, f) multi-mode combination. 


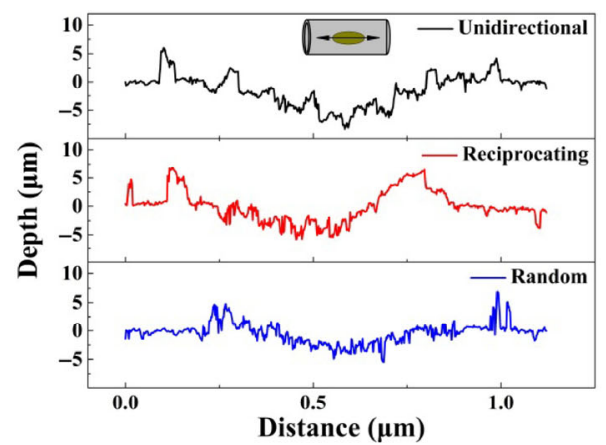

(a) Axial direction

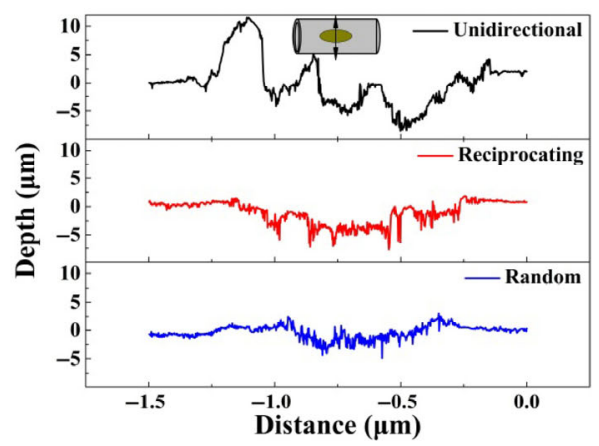

(b) Radial direction

Fig. 14 Profiles of the tube wear scars.

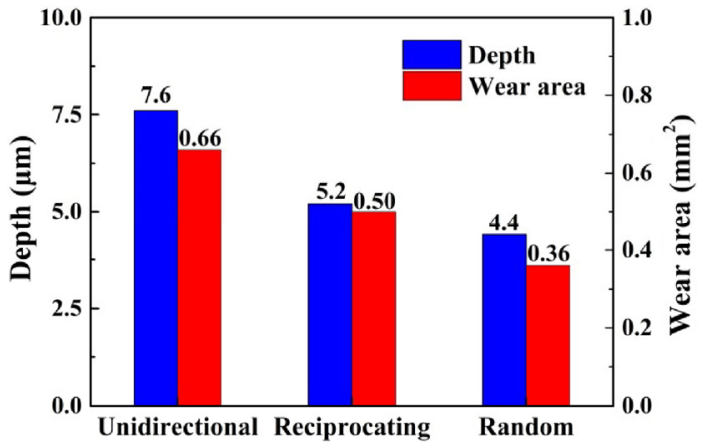

Fig. 15 Wear area and depth of worn wear scars under different motions.

is subjected to two opposite-direction sliding forces, and it forms a protective debris layer on the worn surface. Meanwhile, the accumulation of debris caused the wear area to become rough, and thus, the COF is larger than that in the unidirectional motion test.

\subsubsection{Effect by impact force}

The composite fretting trajectory curves under varied impact forces are shown in Fig. 16. As the impact force increases, the trajectory curve is continuously compressed, and the low straight line continuously increases. That means the actual tangential displacement is continuously increasing, and from $258 \mu \mathrm{m}$ under $15 \mathrm{~N}$ it increases to $321 \mu \mathrm{m}$ under $30 \mathrm{~N}$. When the impact force is of $20 \mathrm{~N}$ and $25 \mathrm{~N}$, the actual tangential displacements are $285 \mu \mathrm{m}$ and $294 \mu \mathrm{m}$, respectively.

The force-time curve under varied impact forces is shown in Fig. 17. The sliding force rises with the increase of impact force, and the ratio (peak COF) of sliding force to impact force is maintained at approximately 0.5 .

Figure 18 shows the SEM micrographs of the worn

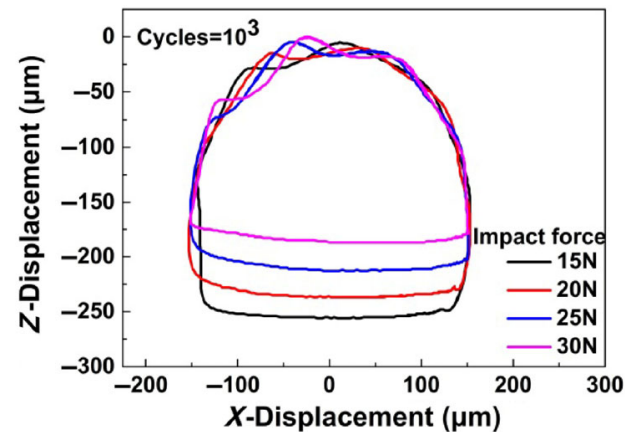

Fig. 16 Composite fretting trajectory curves under different impact forces.

scars under varied impact forces. With the increase in impact force, the impact-sliding compound fretting wear becomes serious. A shallow surface crack (Fig. 18(e)), ploughing (Fig. 18(f)), and delamination (Fig. 18(g)) appeared on the worn surface. The main wear mechanisms are abrasive wear and delamination.

\section{Conclusions}

This study investigated the effect of different complex impact-sliding motions on an Inconel 690 alloy tube. The following conclusions are drawn:

(a) A novel test rig was developed to perform different complex impact-sliding motions. Varied wear modes from unidirectional, reciprocating, and multimode combination motion tests were conducted and measured with the rig.

(b) In the unidirectional motion test, the combined movement is a closed circularity and the sliding force is unidirectional. In the reciprocating motion test, the combined movement is a bidirectional parabola and the sliding force has two directions. In the multi-mode 


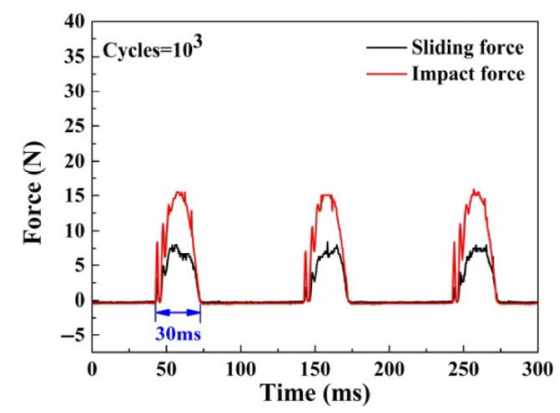

(a) $F_{\text {impact }}=15 \mathrm{~N}$

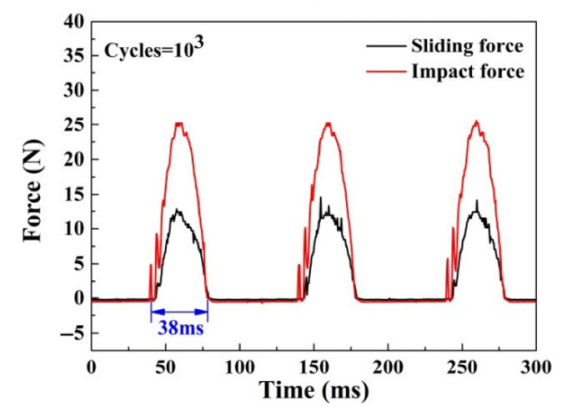

(c) $F_{\text {impact }}=25 \mathrm{~N}$

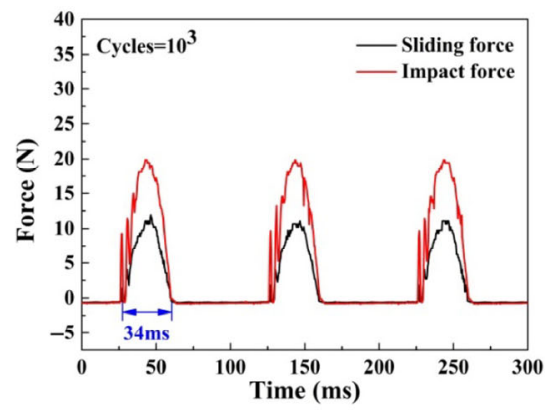

(b) $F_{\text {impact }}=20 \mathrm{~N}$

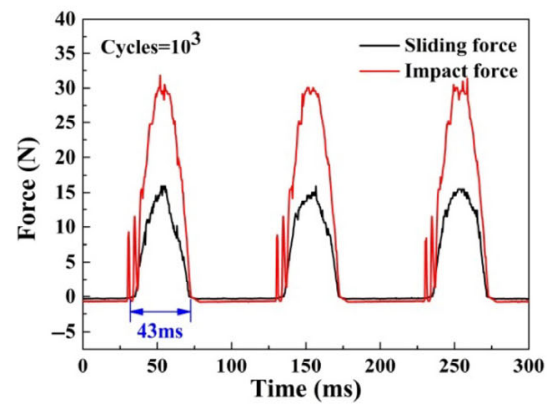

(d) $F_{\text {impact }}=30 \mathrm{~N}$

Fig. 17 Force-time curve under varied impact forces.
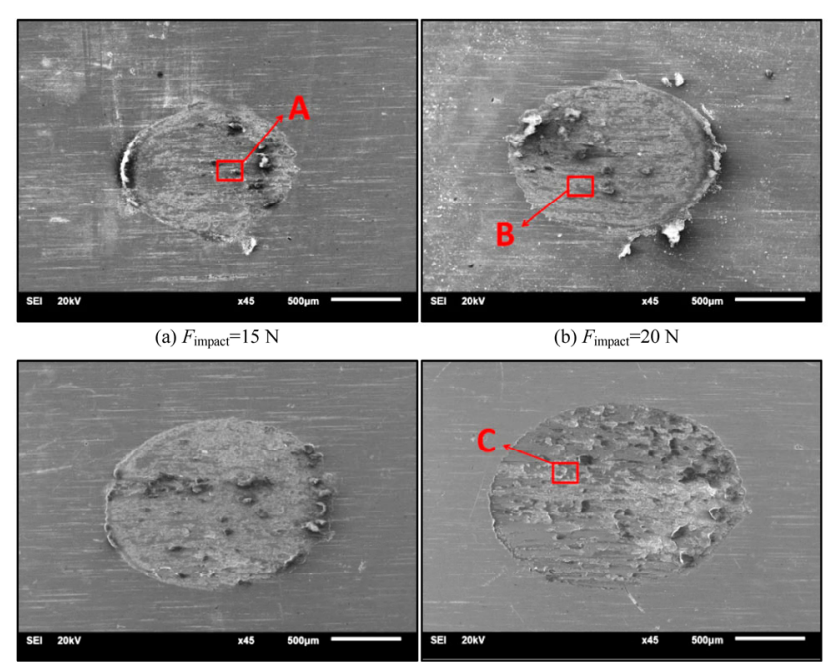

(c) $F_{\text {impact }}=25 \mathrm{~N}$

(d) $F_{\text {impact }}=30 \mathrm{~N}$

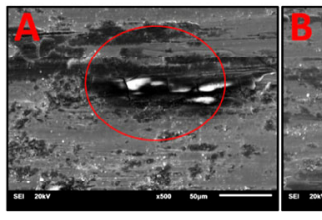

(e) Crack

Ploughing

Fig. 18 SEM micrographs of the worn scars under varied impact forces, cycles $=10^{5}$.

combination motion test, the composed trajectory is different in each cycle.

(c) The Inconel 690 alloy tube was more seriously damaged under unidirectional motion than under reciprocating and multi-mode combination motions, under the same test conditions. The wear debris accumulated in the scar center slowed down the wear and increased the COF. The wear mechanism was mainly abrasive wear and delamination.

\section{Acknowledgement}

This research was supported by the National Natural Science Foundation of China (Nos. 51375407, U1530136, and 51627806), and by the Young Scientific Innovation Team of Science and Technology of Sichuan (No. 2017TD0017).

Open Access: The articles published in this journal are distributed under the terms of the Creative Commons Attribution 4.0 International License (http://creativecommons.org/licenses/by/4.0/), which permits unrestricted use, distribution, and reproduction in any medium, provided you give appropriate credit to the original author(s) and the source, provide a link to the Creative Commons license, and indicate if changes were made. 


\section{References}

[1] Sawyer W G, Argibay N, Burris D L, Krick B A. Mechanistic studies in friction and wear of bulk materials. Annu Rev Mater Res 44(1): 395-427 (2014)

[2] Zhu M H, Zhou Z R. Dual-motion fretting wear behaviour of 7075 aluminium alloy. Wear 255(1-6): 269-275 (2003)

[3] Zhu M H, Zhou Z R, Kapsa P, Vincent L. An experimental investigation on composite fretting mode. Tribol Int 34(11): 733-738 (2001)

[4] Cai Z B, Zhu M H, Zhou Z R. An experimental study of torsional fretting behaviors of LZ50 steel. Tribol Int 43(1-2): 361-369 (2010)

[5] Cai Z B, Zhang G A, Zhu Y K, Shen M X, Wang L P, Zhu $\mathrm{M} \mathrm{H}$. Torsional fretting wear of a biomedical Ti6Al7Nb alloy for nitrogen ion implantation in bovine serum. Tribol Int 59: 312-320 (2013)

[6] Cai Z B, Guan H D, Chen Z Q, Qian H, Tang L C, Zhou Z R, Zhu M H. Impact fretting wear behavior of 304 stainless steel thin-walled tubes under low-velocity. Tribol Int 105: 219-228 (2017)

[7] Lin Y W, Cai Z B, Chen Z Q, Qian H, Tang L C, Xie Y C, Zhu M H. Effect of diameter thickness ratio on alloy Zr-4 tube under impact fretting. Mater Today Commun 8: 79-90 (2016)

[8] Sun Y, Cai Z B, Chen Z Q, Qian H, Tang L C, Xie Y C, Zhou Z R, Zhu M H. Impact fretting wear of Inconel 690 tube with different supporting structure under cycling low kinetic energy. Wear 376-377: 625-633 (2017)

[9] Chen H, Zhao D, Wang Q L, Qiang Y H, Qi J W. Effects of impact energy on the wear resistance and work hardening mechanism of medium manganese austenitic steel. Friction, in press. doi: 10.1007/s40544-017-0158-6 (2017)

[10] Attia M H, Magel E. Experimental investigation of longterm fretting wear of multi-span steam generator tubes with U-bend sections. Wear 225-229: 563-574 (1999)

[11] Green S J, Hetsroni G. PWR steam generators. Int J Multiph Flow 21 Suppl 1: 1-97 (1995)

[12] Lemaire E, Le Calvar M. Evidence of tribocorrosion wear in

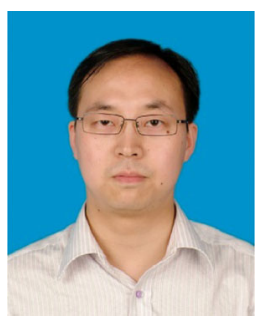

Zhenbing CAI. He received his $\mathrm{PhD}$ degree in materials science from Southwest Jiaotong University, China, in 2009. He joined the Mechanical Engineering School at Southwest pressurized water reactors. Wear 249(5-6): 338-344 (2001)

[13] Hong S M, Kim I S. Impact fretting wear of alloy 690 tubes at $25{ }^{\circ} \mathrm{C}$ and $290{ }^{\circ} \mathrm{C}$. Wear 259(1-6): 356-360 (2005)

[14] Attia H, Gessesse Y B, Osman M O M. New parameter for characterizing and correlating impact-sliding fretting wear to energy dissipation-experimental investigation. Wear 263(1-6): 419-429 (2007)

[15] Attia H. A generalized fretting wear theory. Tribol Int 42(9): 1380-1388 (2009)

[16] Zhang H Y, Lu Y H, Ma M, Li J. Effect of precipitated carbides on the fretting wear behavior of Inconel 600 alloy. Wear 315(1-2): 58-67 (2014)

[17] Ko P L, Wozniewski A, Zhou P A. Wear-corrosion-resistant materials for mechanical components in harsh environments. Wear 162-164: 721-732 (1993)

[18] Zhou J B, Liu J H, Ouyang H J, Cai Z B, Peng J F, Zhu M H. Anti-loosening performance of coatings on fasteners subjected to dynamic shear load. Friction, in press. doi: 10.1007/s40544-017-0160-z (2017)

[19] Rigaud E, Le Bot A. Influence of incidence angle on wear induced by sliding impacts. Wear 307(1-2): 68-74 (2013)

[20] Chen Y, Nie X Y, Leyland A, Housden J, Matthews A. Substrate and bonding layer effects on performance of DLC and TiN biomedical coatings in Hank's solution under cyclic impact-sliding loads. Surf Coat Technol 237: 219-229 (2013)

[21] Chen Y, Nie X Y. Study on fatigue and wear behaviors of a TiN coating using an inclined impact-sliding test. Surf Coat Technol 206(7): 1977-1982 (2011)

[22] Ramalho A, Kapsa P, Bouvard G, Abry J C, Yoshida T, Charpentier M, Bourgeois M. Effect of temperatures up to $400{ }^{\circ} \mathrm{C}$ on the impact-sliding of valve-seat contacts. Wear 267(5-8): 777-780 (2009)

[23] Reynier B, Phalippou C, Riberty P, Sornin J. Influence of a periodic latency time on the impact/sliding wear damage of two PWR control rods and guide cards specimens. Wear 259(7-12): 1314-1323 (2005)

[24] Levy G, Morri J. Impact fretting wear in $\mathrm{CO}_{2}$-based environments. Wear 106(1-3): 97-138 (1985)

Jiaotong University from 2009. His current position is a professor and the deputy director of the Tribology Research Institute.

His research areas cover the tribology of electrical contact system, aviation and nuclear power equipment. 


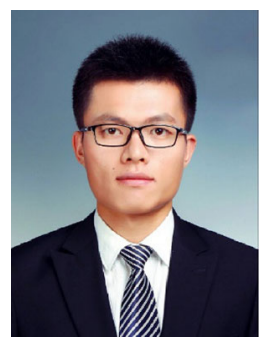

Zhiqiang CHEN. He received his bachelor degree in mechanical engineering in 2014 from Henan Polytechnic University, Jiaozuo, China. He has recently obtained his

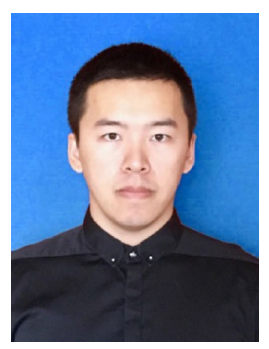

Yang SUN. He received his bachelor degree in ground weapon mobile engineering in 2013 from Beijing Institute of Technology, Beijing, China. Recently, he is studying

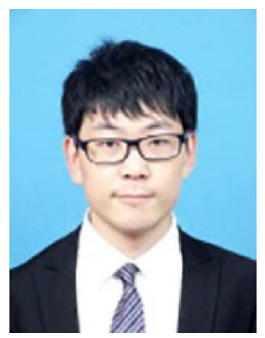

Jianying JING. He received his bachelor degree in mechanical engineering in 2016 from Harbin Institute of Technology, harbin, China. Recently, he is studying

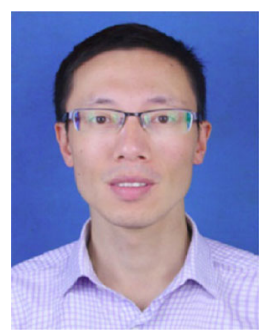

Jinfang PENG. He received his bachelor degree in material science and engineering in 2006 from Southwest Jiao Tong University, Chengdu, China. After then, he has recently

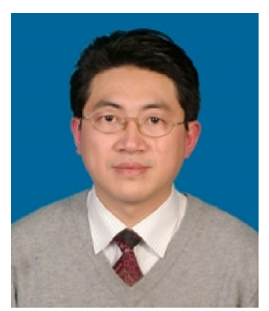

Minhao ZHU. He received his M.S. and $\mathrm{PhD}$ degrees in metal material and heat treatment from Southwest Jiao Tong University, Chengdu, China, in 1993 and 2001, respectively.
M.S. degree in mechanical engineering at Southwest Jiaotong University, Chengdu, China. His research interests include microelectromechanical systems and tribology.

for a master degree at the Institute of Tribology at Southwest Jiao Tong University. His research interests include impact fretting tribology and electromechanical equipment development.

for a master degree at the Institute of Tribology at Southwest Jiao Tong University. His research interests include equipment development and impact-sliding fretting tribology.

obtained his $\mathrm{PhD}$ degree in materials science at Southwest Jiao Tong University. His current position is a research assistant. His research interests include fretting fatigue and failure analysis.

He joined the Institute of Tribology at Southwest Jiao Tong University from 1997. His current position is a professor. His research areas cover the engineering materials for tribological surfaces. 